\title{
Twelve tips for taking effective Lectures
}

\author{
Swapnil Paralikar \\ Assistant Professor, Dept. of Physiology, Government Medical College, Bhavnagar, Gujart, India
}

Corresponding Author:

Email: drsparalikar@gmail.com

\begin{abstract}
Lectures are ubiquitous and here to stay. The traditional lecture is not so effective in developing the vital skill of critical thinking in medical students. In addition, students are passive recipients of information in such a lecture.

In this article, a number of tips have been put forth to make the traditional lecture effective (facilitate learning). These include preparing adequately for a lecture, explaining clearly and in an interesting manner, using educational media effectively, planning the opening of the lecture, giving analogies and using extra-verbal messages effectively. Obtaining feedback through microteaching (MT2), and reflecting on one's performance are also required to advance one's skill at lecturing.
\end{abstract}

"A good lecture is like a miniskirt; long enough to cover the subject, but short enough to be interesting."

Adapted from TED speaker Celeste Hadlee's quote on a conversation in her TED

Talk ' 10 ways to have a better conversation.'

In medical education, lectures have had a place from its very inception. Even today, lectures are an important way of teaching in most medical schools around the world.

Lectures have been found to be as effective as other teaching methods in teaching medicine and allied subjects. ${ }^{2}$ Lectures ensure that the topics of the syllabus are covered, and regular lectures motivate the students to learn the subject. In pre- and para-clinical sciences, lectures taken well may help in understanding of concepts or phenomenon.

There is an old adage that states, 'Lectures are a method of transferring the notes of a teacher to the notes of a student without passing through the heads of either.' ${ }^{3}$

Traditionally taken lectures are a one-way traffic from the teacher to the student. They induce passivity and compliance in the student. These lectures do not provide a context for learning to the students, and can hence, engender a sense of inadequacy and impotence in the learners. ${ }^{4}$

\section{Tip 1: Prepare, prepare and prepare}

Adequate preparation is the first and most important step in taking an effective lecture.

The maxim is 'Know your subject, know your student.' ${ }^{2}$ The teacher is expected to be an expert in his subject. Before taking a lecture on diabetes mellitus, a physician may need to brush up his knowledge on the mechanism of action of insulin, which he should certainly do. One should also be aware of the knowledge the student possesses on the subject. A physiologist may do well to know what the students have learnt regarding insulin and blood glucose in the high school.

\section{Tip 2: Clearly state the learning objectives}

A set of learning objectives at the beginning of the lecture will help the student know what he is supposed to learn in the lecture.

\section{Tip 3: Plan the opening of the lecture}

The opening catches the attention of the audience. The billionaire and philanthropist Bill Gates commenced a TED Talk on malaria by opening a box containing a swarm of mosquitoes. No wonder the audience got interested and it is one of the most watched TED Talks ever.

For a TED Talk on Spatial Memory, the speaker began with a picture of a big parking lot, and posed the question 'How does one find one's car in the parking lot? ${ }^{4}$

A lecture by a public health professional on diabetes mellitus to Indian medical students may begin with a statement, 'By 2020, one in every five diabetics in the world will be an Indian.'

\section{Tip 4: Be clear}

The lecture may be made more clear to the students by using a model proposed Ronald Harden - signposts, frames, foci and links. ${ }^{2}$

In a lecture on coronary disease, for the section on risk factors, these may be as follows:

Signposts: I will be now explaining the risk factors for coronary artery disease.

Foci: Summarizing the risk factors

Links: Two week ago, I came across a patient who was a heavy smoker, did not engage in any kind of physical exercise and had a BMI of $32 \mathrm{~kg} / \mathrm{m}^{2}$. His blood pressure was $150 / 100 \mathrm{mmHg}$ and he had chest pain at rest. Thus, he had many of the risk factors, and hence, had developed coronary artery disease.

Frames: stating explicitly that one has now completed explaining the etiology of 
coronary artery disease

\section{Tip 5: Be Interesting}

A lecturer can make the topic interesting by using analogies (comparisons), telling an anecdote about a patient one saw, stating an interesting quote, and so on. Example:

$\checkmark \quad$ I begin my lecture on the regulation of heart rate (while teaching of the cardiovascular system in physiology) by telling the story of German physiologist and Nobel Laureate, Otto Loewi. Loewi had a dream on the night of Easter Sunday in 1920 that an agent is released from the vagus nerve which decreases the heart rate. He performed an experiment to establish the fact and called the agent 'Vagustoffe.' Later, it was christened 'Acetylcholine.'

$\checkmark \quad$ To emphasize the role of physical exercise in noncommunicable diseases -

'It is not that diabetes, obesity and heart disease run in your family. It is that no one runs in your family.'

\section{Tip 6: Take an Interactive Lecture}

Interactivity implies a two-way communication between the teacher and student. Methods for taking an interactive lecture include:

a. Questioning

b. Think, pair and share

c. Buzz Groups

d. Jigsaw Technique

The interactivity should be planned while preparing for the lecture.

\section{Tip 7: Use Educational Media Effectively}

Effective use of educational media like power point involves applying the LIGHT principles. ${ }^{4}$

L: Teaching materials should be Linked to the talk

I: Teaching material should be Interesting

G: There should be a uniform $\underline{\mathbf{G}}$-neral Style

H: Important points should be $\underline{\text { highlighted }}$

T: Targetted to the audience

\section{Tip 8: Use extra- verbal messages}

A lecturer should use extra-verbal messages like emphatics, expressiveness, hesitation and stumbles appropriately and judiciously.

\section{Tip 9: Monitor the students' performance}

A lecturer should monitor the students' performance and make appropriate changes to the delivery of the lecture. Puzzlement, boredom and talking in class are an indicator that the students are not following what is being taught in the class. This is the precise reason why live lectures are preferred to recorded lectures.

\section{Tip 10: Do not overload information}

The brain has a limited capacity of memory. At one go, it can store seven bytes of information.

\section{Tip 11: Obtain Feedback}

Feedback from peers can be best sought by using a model of microteaching called as $21^{\text {st }}$ century Microteaching or MT2, proposed by Allen and Wang. ${ }^{5}$ This is a modified version of the original model of Microteaching proposed by Allen and Ryan at Stanford University in the 1960s. They modified the model because of the fallacies which they observed.

The guiding principles of MT2 are:

$\checkmark \quad$ The session should be conducted in a friendly and non-threatening environment.

$\checkmark \quad$ The teacher should volunteer for the microteaching session and should not be forced upon.

$\checkmark$ Only one or two skills (e.g. opening of the lecture, explanation) should be assessed.

$\checkmark \quad$ Three-four peer should provide feedback, who themselves should subsequently volunteer for the microteaching session.

$\checkmark \quad$ Each peer should state only-two positive points and two negative points.

$\checkmark$ Feedback should be given in a non-judgemental manner.

Structured feedback can also be obtained from students. ${ }^{3}$

\section{Tip 12: Reflection}

The lecturer can learn from his past experience by reflecting on it. He may reflect on various aspects of the lecture and gain new insights or perspectives. This creative process is called as wisdom or artistry. ${ }^{6}$ A proposed model for reflection could be:

i. What happened?

ii. So what?

iii. What next?

\section{References}

1. www.ted.com ( Last accessed on $31^{\text {st }}$ May, 2017)

2. Brown GA, Manogue M: AMEE medical education guide No. 22: Refreshing Lecturing: a guide for lecturers, Medical Teacher 24: 231-244,2001.

3. Brown G, Edmunds S: Lectures in Dent JA, Harden RM (eds): A Practical Guide for Medical Teachers. $4^{\text {th }}$ edition. London: Elsevier; 2013 pp 61-68.

4. Farrow R. Creating teaching materials in Cantillon $P$, Hutchinson L, Wood D(eds): ABC of Teaching and Learning in Medicine, $1^{\text {st }}$ edition London: BMJ Publishing Group; 2003 pg.46-8.

5. Singh T: Microteaching Revisited. The National Medical Journal of India, 2004;24:292-3.

6. Long A, Lock B: Lectures and large groups in Swanwick Tim (editor): Understanding Medical Education: evidence, theory and practice, West Sussex, 2014, WileyBlackwell, pg. 137-43. 